\title{
The Cardiomyopathy in Friedreich's Ataxia: Isotopic Ventriculography and Myocardial Imaging with Thallium-201
}

\author{
L. Therriault, G. Lamoureux, M. Côté, G. Plourde and B. Lemieux
}

\begin{abstract}
Myocardial scanning after the intravenous administration of Thallium 201 was used to evaluate regional myocardial perfusion in 14 patients with Friedreich's ataxia. Isotopic ventriculography was also used to assess left ventricular contractility. Myocardial images in patients with Friedreich's ataxia were found to be precociously abnormal irrespective of the degree of neurological impairment or of the severity of myocardial hypertrophy.
\end{abstract}

RÉSUMÉ: Chez 14 patients souffrant d'ataxie de Friedreich, nous avons évalué la perfusion myocardique régionale après administration intraveineuse de Thallium 201. Nous avons aussi utilisé la ventriculographie isotopique pour évaluer la contractilité ventriculaire gauche. Chez les patients avec Friedreich, les images myocardiques s'avérèrent précocément anormales, indépendamment du degré d'atteinte neurologique ou de la sévérité de l'hypertrophie du myocarde.

Can. J. Neurol. Sci. 1984; 11:588-591

Friedreich's Ataxia is associated with a cardiomyopathy caracterized by mild to moderate left ventricular hypertrophy. The hypertrophy is most often concentric with some cases associated with asymetrical septal hypertrophy and subaortic stenosis (Thoren, 1964 Côté, 1979). The large and small intramural coronary arteries, in our experience, do not present signifiant atherosclerotic involvement (Lamarche, 1980). We used myocardial scanning after the intravenous administration of Thallium 201 to evaluate regional myocardial perfusion and isotopic ventriculography to assess left ventricular contractility and to establish a correlation, if any, between the severity of the cardiomyopathy with age and degree of neurological impairment of these patients.

\section{METHODS AND MATERIALS}

Fourteen patients with classical Friedreich's ataxia were evaluated. The degree of neurological impairment was assessed by using the clinical staging of functional ability described by Suringard and co-workers (Suringard, 1957). For example, in stage 3 , the patient may walk and arise from a chair without support, in stage 8 the patient is completly bedridden. Echocardiograms were obtained using a Smith-Kline-French Ekoline 20 or a Hewlett Packard 77020 echocardiograph. Thallium images were acquired after the intravenous injection of 1.6 to $2.5 \mathrm{mCi}$ of Thallous chloride -201 by means of a high resolution scintillation camera (Picker Dyna Camera 4) for 3000 counts per $\mathrm{cm}^{2}$ per projection. Images were obtained in the anterior, 25,45 and 65 degree left anterior oblique and left lateral projections. After back-ground correction, the images were quatitatively analyzed and segmental thallium activity in each projection compared to normals (mean $\pm 2 \mathrm{SD}$ ). Left ventricular ejection fraction was determined from the gated cardiac blood pool scan after the injection of 15 to $20 \mathrm{mCi}$ of ${ }^{99 \mathrm{~m}} \mathrm{Tc}, 20$ minutes after a previous injection of stannous chloride.

RESULTS

Table 1:

\begin{tabular}{lcccccccccccccc}
\hline \hline CASE & 1 & 2 & 3 & 4 & 5 & 6 & 7 & 8 & 9 & 10 & 11 & 12 & 13 & 14 \\
SEX & F & F & F & F & F & F & F & F & M & M & F & F & M & F \\
AGE & 31 & 20 & 20 & 19 & 15 & 19 & 13 & 16 & 22 & 18 & 29 & 34 & 27 & 12 \\
STAGE & 8 & 5 & 6 & 6 & 5 & 6 & 4 & 5 & 6 & 6 & 7 & 8 & 5 & 3 \\
\hline
\end{tabular}

All patients in this study had typical Friedreich's ataxia and were part of the Quebec Cooperative Study on Friedreich's 
Table 2:

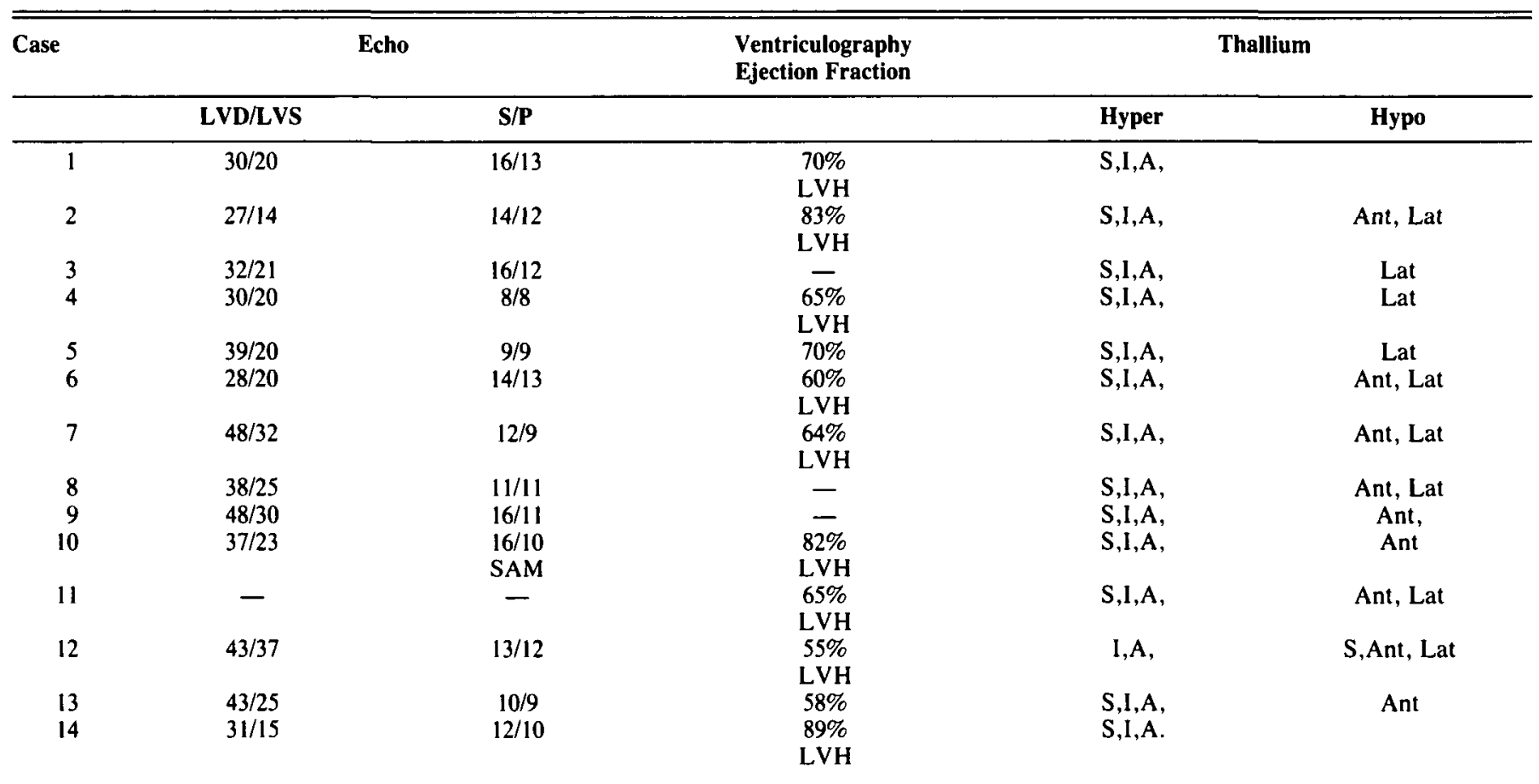

LEGEND: Echo: Echocardiography; LVD: Left ventricular internal diastolic diameter in mm; LVS: Left ventricular internal systolic diameter in $\mathrm{mm}$;S: Diastolic septal thickness in mm; P: Diastolic posterior wall thickness in mm; SAM: systolic anterior motion of the anterior leaflet of the mitral valve; LVH: Left ventricular hypertrophy; HYPER: Relative hyperfixation; HYPO: relative hypofixation; S: Septal wall; I: Inferior wall; A: Apex; Ant: Anterior wall; Lat: Lateral wall.

Ataxia. There were 11 females and 3 males with a mean age of 20 (range 12 - 34). The majority were in the functional stage 5 and 6 , being confined to a wheelchair with varying degrees of autonomy.

Echocardiographic data was available in 13 cases. There was no left ventricular dilatation but left ventricular hypertrophy (LVH) was observed in 10 cases, discrete in 8 and moderate in 2 cases. Asymetrical septal hypertrophy (ASH) defined as a ratio of septal to free posterior wall thickness greater than 1.3 was present in 4 patients (cases $3,7,9,10$ ) but only one (case 10) depicted systolic anterior motion of the anterior leaflet of the mitral valve (SAM) suggestive of subaortic stenosis. No significant hypertrophy was present in 3 cases. Isotopic ventriculography revealed normal ejection fractions (greater than $50 \%$ ) in all 11 cases available (mean 69\%, range 55-89). Because of arrythmias, adequate gated cardiac blood pool images could not be obtained in 3 patients. In the highest range, we find the youngest patient and the case with ASH and SAM; in the lower ranges, the two oldest, aged 34 and 27 respectively. Associated left ventricular hypertrophy is suggested in 9 cases. The Thallium-201 myocardial perfusion images were abnormal in all cases when compared to normal distribution patterns. The segmental circumferential profile curves of the Friedreich's ataxia patients uniformly depicted a relative hyperfixation in the infero-apical regions of the left ventricle and also in the interventricular septum mainly its posterior region. Although the hyperfixation was most prominent in cases with moderate hypertrophy (in particular the patient with ASH), the abnormal distribution was observed even in those cases without hypertrophy as defined by echocardiography particularly in the apical region. Relative hypoperfusion distribution patterns were observed in 10 cases usually in the antero-lateral segments of the left ventricule.

\section{Discussion}

In almost all cases of Friedreich's ataxia, there is evidence of myocardial involvement. The results of this study confirms that the cardiomyopathy is characterized in most cases by a mild to moderate hypertrophy of the left ventricle rarely obstructive. The systolic function of the left ventricle seems well preserved as documented by echocardiography and isotopic ventriculography. Indeed assesment of left ventricular contractility by mesuring ejection fractions revealed normal values in all patients without regional abnormalities of contraction. Patients in the early stages of the disease or those with an obstructive cardiomyopathy may even reveal hyperkinesis with high ejection fractions. Contractility however appears to progressively decrease with age. Isotopic ventriculography is a useful diagnostic method to evaluate regional wall motion and contractility particulaly in those patients whose severe thoracic scoliosis makes adequate echocardiographic examination difficult. These findings concur with those of Pentland who observed normal ventricular function in fifteen of seventeen patients. Two patients, however, with discrete hypertrophy had regional areas of hypokinosis. (Pentland, 1983). 


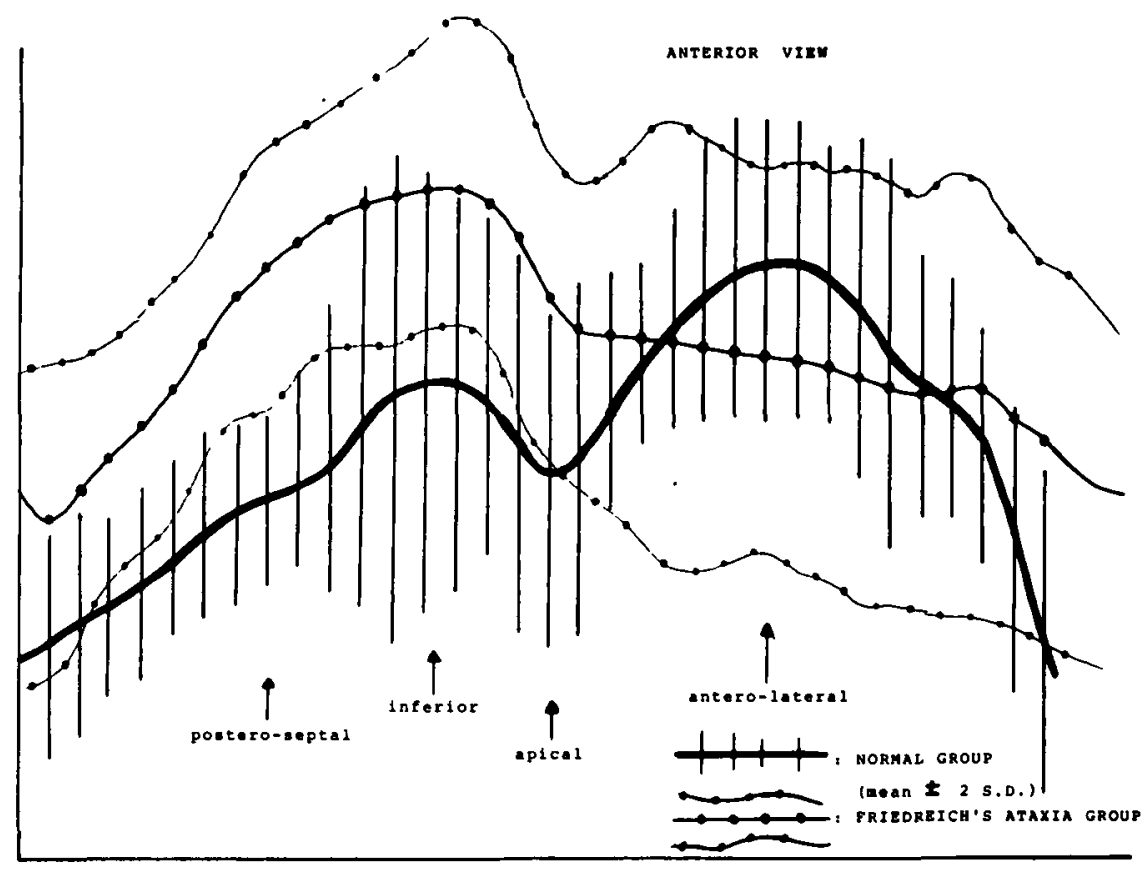

Figure 1 - Profile activitycurves (mean \pm 2 s.d.) obtained from the anterior views of the 20I-TI scans in the Friedreich's ataxia group as compared to a normal group of patients. Note the significant "increase" in activity along the postero-septal, inferior and apical wall in the ataxia group.

Thallium 201 myocardial perfusion images revealed abnormal distribution patterns in all cases. Thallium, a potassium analog, is rapidly extracted by the myocardial cell. (Berger, 1981). Regional myocardial concentration is dependent on many factors including, regional coronary blood flow, rate of myocardial uptake and efflux, the integrity of membrane-bound sodiumpotassium-ATP-ase system and intracellular $\mathrm{pH}$. In these patients with Friedreich's ataxia, there was a constant abnormality in the regional distribution of Thallium when compared to normals while at rest. Previous studies did not reveal significant involvement of large, medium and small coronary arteries which would suggest obstructive abnormalities to coronary flow. (Lamarche, et al., 1980, Sanchez-Casis et al, 1976). The myocardial images obtained and the computer-analysis of the segmental distribution curves were suggestive of a relative regional increased uptake of Thallium-201 as opposed to the defects observed in patients with myocardial infarction or ischemia during exercise. The abnormal perfusion images could be secondary to myocardial hypertrophy, however in patients with idiopathic hypertrophic subaortic stenosis and concentric hypertrophy the myocardial scans, albeit demonstrating hypertrophy, may reveal normal distribution patterns (Rubin et al. 1979, Bulkley et all 1975). Furthermore, our cases without hypertrophy also had abnormal "hyperfixation" regions of the myocardium when compared to the curves derived from computer-analysis of segmental distribution of Thallium uptake. No apparent correlation exists between the age of the patient, the degree of hypertrophy and these uniform regional abnormalities of Thallium-201 relative distribution in patients with Friedreich's ataxia.

These findings suggest that, like the ECG, Thallium 201 myocardial images in patients with Friedreich's ataxia are precociously abnormal irrespective of the degree of neurological impairment or severity of myocardial hypertrophy. The cardiomyopathy appears to be slowly progressive with preservation

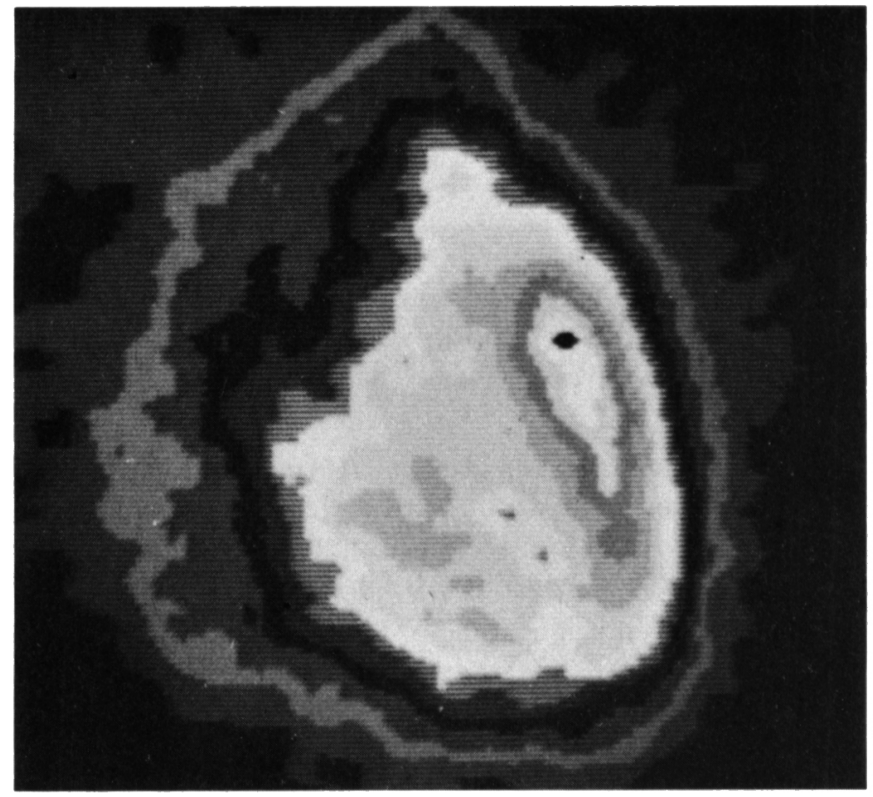

Figure 2 - Typical anterior view on 201 -Tl study in a normal patient. Note the relative hyper-activity along the anterolateral wall as compared to the apex, the inferior and the postero-septal wall.

of left ventricular contractility, as demonstrated by isotopic ventriculography, even in the oldest patients. Although the qualitative abnormal Thallium uptake images are evident, one may only speculate about a possible quantitative increased uptake and regional concentrations of this potassium analog by the myocardium in Friedreich's ataxia. Previous hemodynamic, angiography and pathological data make it unlikely that a vascular anormaly exists to explain these abnormal Thallium scans (Côté, 


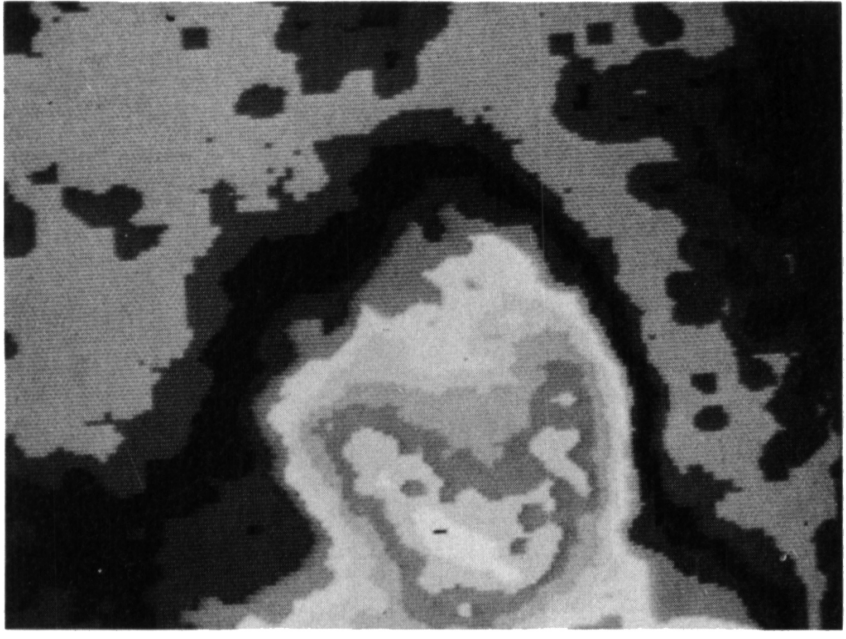

Figure 3-Typical anterior view of the heart of a patient with Friedreich's ataxia. Note the relative hyper-activity now located along the apex, the inferior and postero-septal wall as well as the normal physiologic activity in the stomach in this non-fasting patient.

1976). More likely these abnormal Thallium distribution patterns may reflect "in vivo" the many postulated primary metabolic abnormalities leading to a low grade and chronic "mitochondrial energy deprivation"' (Barbeau, 1980).

\section{REFERENCES}

Barbeau A, (1980) Friedreich's Ataxia 1980. An overview of the pathophysiology. Can J Neurol Sci 7:455-468.

Berger HJ, Zaret BL (1981) Nuclear Cardiology - New Eng J Med 305:799-807.

Bulkley BH, Rouleau J, Strauss HW, Pitt B (1975) Idiopathic hypertrophic subaortic stenosis; detection by Thallium-201 Myocardial perfusion imaging. New Eng J Med 293: 1113-1116.

Côté M, Bureau M, Leger C, Martin J, Gattiker H, Cimon M, Larose A, Lemieux B (1979) Evolution of cardio-pulmonary involvement in Friedreich's ataxia. Can J Neuro Sci 6:151-157.

Côté M, Davignon A, Elias G, Solignac A, Geoffroy G, Lemieux B, Barbeau A (1976) Hemodynamic findings in Friedreich's Ataxia. Can J Neurol Sci 3:333-336.

Lamarche JB, Côté M, Lemieux B (1980) The cardiomyopathy of Friedreich's ataxia-Morphological observations in 3 cases. Can J Neuro Sci 7:389-396.

Pentland B, Fox KAA (1983) The heart in Friedreich's ataxia. J Neurol Neurosurg Psych 46:1138-1142.

Rubin KA, Morrison J, Padnick MB (1979) Idiopathic hypertrophic subaortic stenosis; Evaluation of anginal symptoms with Thallium-201 myocardial imaging. Amer J Cardiol 44:1040-1045.

Sanchez-Casis G, Côté M, Barbeau A (1976) Pathology of the heart in Friedreich's ataxia; Review of the litterature and report of one case. Cass J Neurol Sci 3:349-354.

Suringard CA, Dewer GG, Greenspan L (1957) Gradients of functional ability of importance in rehabilitation of patients with progressive muscular and neuromuscular diseases. Archives of Physical Medecine and Rehabilitation 574-579.

Thoren C (1964) Cardiomyopathy in Friedriech's Ataxia: with studies of cardiovascular and respiratory functions. Acta Pediatrica (Suppl) 53-153. 